\title{
Mitogen-activated protein kinase (MAPK) blockade of bovine preimplantation embryogenesis requires inhibition of both p38 and extracellular signal-regulated kinase (ERK) pathways
}

\author{
Pavneesh Madan, Michele D Calder and Andrew J Watson \\ Departments of Physiology and Pharmacology and Obstetrics and Gynecology, University of Western Ontario, \\ Child Health Research Institute, 5th Floor Victoria Research Laboratories, 800 Commissioners Road East, London, \\ Ontario, Canada, N6A 4G5
}

(Correspondence should be addressed to A J Watson; Email: awatson@uwo.ca)

\begin{abstract}
Blastocyst formation, as a critical period during development, is an effective indicator of embryonic health and reproductive efficiency. Out of a number of mechanisms underlying blastocyst formation, highly conserved mitogen-activated protein kinase (MAPK) signaling has emerged as a major mechanism involved in regulating murine preimplantation embryo development. The objective of our study was to ascertain the role of MAPK signaling in regulating bovine development to the blastocyst stage. Using reverse transcriptase PCR and immunohistochemical staining procedures we have demonstrated that mRNA transcripts and polypeptides encoding p38 MAPK pathway constituents are detectable in preimplantation bovine embryos from the one-cell to the blastocyst stage. Further, the effects on bovine embryo development following inhibition of $p 38 \alpha / \beta$ and extracellular signal-regulated kinase (ERK) signaling by treatment with SB220025 and U0126, respectively, were investigated. Eight-cell bovine embryos (50 per group; three replicates) were placed into treatments consisting of synthetic oviductal fluid (SOF) medium: SOF + SB202474 (inactive analogue), SOF + SB220025, SOF + U0124 (inactive analogue), SOF + U0126, and SOF + SB220025 + U0126. Inhibition of p38 MAPK or ERK signaling individually did not affect development to the blastocyst stage. However, when both pathways were blocked simultaneously there was a significant reduction $(\boldsymbol{P}<\mathbf{0 . 0 5})$ in blastocyst formation, cell number and immunofluorescence of phosphorylated downstream pathway constituents. We have determined that, in variance to what was observed during murine preimplantation development, bovine early embryos progress at normal frequencies to the blastocyst stage in the presence of p38 MAPK inhibitors.

Reproduction (2005) 130 41-51
\end{abstract}

\section{Introduction}

Preimplantation embryogenesis, defined as the time interval from conception to nidation or attachment of the embryo to the uterus, is an important determinant of embryonic health and reproductive efficiency. This period is characterized by the development of the fertilized zygote through cleavage divisions, the activation of embryonic transcription, and the morphogenetic events of compaction and cavitation, which result in the formation of the blastocyst. Any aberration in the cascade of events during this critical period of blastocyst formation and hatching has a deleterious affect on the developmental potential and/or the survival of the embryo (Niemann \& Wrenzycki 2000, Watson \& Barcroft 2001, Niemann et al. 2002). Therefore, understanding the signals that regulate preimplantation embryogenesis is key in comprehending the spatiotemporal progression of the early embryo.
The mitogen-activated protein kinase (MAPK) pathways transmit responses from ligand-receptor interactions and convert them into a variety of cellular responses ranging from apoptosis to immune response as well as growth and differentiation, cytoskeletal re-arrangements and cell proliferation (Kyriakis \& Avruch 2001, Zhang \& Liu 2002, Cowan \& Storey 2003, Ravingerova et al. 2003). The MAPK superfamily of proteins consists of four separate signaling cascades: the c-Jun $\mathrm{N}$-terminal kinase or stress-activated protein kinases (JNK/SAPKs; Woodgett et al. 1996, Whitmarsh \& Davis 2001), the extracellular signal-regulated kinases (ERKs; Boulton \& Cobb 1991, Pouyssegur et al. 2002), the ERK5 or big MAP kinase 1 (Lee et al. 1995, Zhou et al. 1995), and the p38 MAPK group of protein kinases (Han et al. 1994), all of which are highly conserved throughout eukaryotic systems (Kyriakis \& Avruch 2001). 
We have demonstrated recently that all principal constituents of the p38 MAPK family are expressed throughout murine preimplantation development (Natale et al. 2004). This subfamily of the MAPK includes four protein isoforms, p38 $\alpha, \beta, \gamma$, and $\delta$, that regulate cellular processes such as inflammation and cytoskeleton re-arrangements as well as cell proliferation and apoptosis (Enslen et al. 2000, Ono \& Han 2000, Kyriakis \& Avruch 2001). p38 MAPK further regulates actin filament formation through MAPKAPK 2/3 (MK2) or MAPKAPK 5 (PRAK) and subsequently through heat-shock protein (Hsp) 25/27 (Lavoie et al. 1995, Guay et al. 1997, Huot et al. 1998, DalleDonne et al. 2001, Khurana \& Dey 2003). More importantly we have discovered that inhibition of p38 MAPK activity during murine preimplantation development results in a blockade of development at the eight-to-16-cell stage that is fully reversible for at least a 48-h treatment interval (Natale et al. 2004, Paliga et al. 2005). These results have implicated p38 MAPK as an important regulator of filamentous actin and of preimplantation development in mice (Natale et al. 2004). The effects of p38 MAPK inhibition on filamentous actin can be observed within $3 \mathrm{~h}$ of treatment with p38 MAPK inhibitors applied to eight-cell-stage murine embryos and this is accompanied by a decline in phosphorylated MAPKAPK 2/3 and Hsp25/27 (Paliga et al. 2005). All of these effects of p38 MAPK inhibition were reversible upon removal of the inhibitor and development resumed in a delayed but normal fashion to the blastocyst stage (Natale et al. 2004, Paliga et al. 2005).

During the last decade, production of bovine embryos in vitro has become a routine research method in many laboratories, and is also being adopted in applied breeding programs; however, there is dearth of information related to understanding the mechanisms that regulate bovine blastocyst formation. Perhaps of even greater importance is the need to define common mechanisms of regulation across all species so that insight relevant to improving our understanding of early development in the human can be discerned. Therefore, the objective of the present study was to investigate the role of MAPK signaling during bovine preimplantation embryo development. Surprisingly, we have determined, that in variance to what was observed during murine preimplantation development, bovine early embryos progress at normal frequencies to the blastocyst stage in the presence of p38 MAPK inhibitors.

\section{Materials and Methods \\ Production of bovine embryos in vitro}

Bovine ovaries were transported from an abattoir in sterile saline at $32-37^{\circ} \mathrm{C}$ for oocyte collection using standard protocols as described previously (Giritharan \& Rajamahendran 2001). Briefly, cumulus-oocyte complexes (COCs) from small follicles $(3-6 \mathrm{~mm})$ were aspirated into the follicular aspiration medium consisting of Dulbecco's PBS (Gibco BRL; Invitrogen, Burlington, ON, Canada), 0.3\% BSA (Sigma-Aldrich Canada, Oakville, ON, Canada) and $50 \mu \mathrm{g} / \mathrm{ml}$ gentamycin (Sigma-Aldrich, Canada) using an 18 gauge needle attached to vacuum suction apparatus. COCs that contained an oocyte with an evenly granulated cytoplasm and surrounded by more than three layers of cumulus cells were selected for maturation in vitro. For maturation and fertilization, standard insemination and embryo-culture protocols were used as described previously (Vigneault et al. 2004)

Briefly, the COCs were cultured in oocyte maturation medium composed of modified synthetic oviductal fluid (SOF) medium (Holm et al. 1999) with 0.8\% BSA, modified Eagle's medium (MEM), non-essential amino acids (Gibco), MEM essential amino acids (Gibco), $1 \mathrm{mM}$ glutamine, $0.5 \mu \mathrm{g} / \mathrm{ml}$ follicle-stimulating hormone (FSH) and $1 \mu \mathrm{g} / \mathrm{ml} 17 \beta$-estradiol. About 50 COCs were placed in each well of a four-well culture plate and incubated in a humidified atmosphere for $24 \mathrm{~h}$ at $38.5^{\circ} \mathrm{C}$ and an atmosphere of $5 \% \mathrm{CO}_{2}$ in air.

About 50 mature COCs were added to $330 \mu$ drops containing modified Tyrode lactate medium (TLH) supplemented with $0.6 \%$ fatty acid-free BSA (Sigma-Aldrich), $0.2 \mathrm{mM}$ pyruvic acid, $10 \mu \mathrm{g} / \mathrm{ml}$ heparin and $50 \mu \mathrm{g} / \mathrm{ml}$ gentamycin under mineral oil. Frozen semen was thawed at $37^{\circ} \mathrm{C}$ for $1 \mathrm{~min}$ and placed at the bottom of a $5 \mathrm{ml}$ tube containing TLH. After $90 \mathrm{~min}$ of incubation at $38.5^{\circ} \mathrm{C}$ and $5 \% \mathrm{CO}_{2}$ the spermatozoa that had 'swum up' were collected and centrifuged at $250 \mathrm{~g}$ for $5 \mathrm{~min}$ at room temperature. The supernatant was discarded and sperm pellet were re-suspended in $1 \mathrm{ml}$ TLH medium. Sperm number was counted using a hemocytometer to obtain a final concentration of $1 \times 10^{6}$ spermatozoa $/ \mathrm{ml}$ in the COC drop. The co-incubation of spermatozoa and COCs was carried out in humidified air at $38.5^{\circ} \mathrm{C}$ and an atmospshere of $5 \%$ $\mathrm{CO}_{2}$ in air for $15-18 \mathrm{~h}$.

Following fertilization, presumptive zygotes were denuded by vortexing, washed three times in culture media containing SOF medium containing 0.8\% BSA, MEM non-essential amino acids, $1 \mathrm{mM}$ glutamine, $1.5 \mathrm{mM}$ glucose and $10 \mu \mathrm{M}$ EDTA (called SOF1 medium). Subsequently, 20-30 presumptive zygotes were transferred to each $50 \mu \mathrm{l}$ culture drop under mineral oil and cultured at $38.5{ }^{\circ} \mathrm{C}, 5 \% \mathrm{CO}_{2}$, and humidified air with reduced-oxygen atmosphere $(7 \%)$. After $72 \mathrm{~h}$ of culture, SOF1 medium was replaced with SOF2 medium, which contained $0.8 \%$, BSA, MEM non-essential amino acids, MEM essential amino acids, $1 \mathrm{mM}$ glutamine and $1.5 \mathrm{mM}$ glucose. This is done to prevent toxicity due to ammonium accumulation resulting from amino acid degradation (Vigneault et al. 2004) and the efficacy of SOF in bovine in vitro embryo development has been demonstrated previously (Ali \& Sirard 2002). Batches of 20 embryos were harvested at timed stages of development (two, four, and eight cells, morulae, and blastocysts) for RNA extraction or immunohistochemistry. 


\section{Primer design}

Primer sets were designed to recognize and amplify conserved nucleotide sequences encoding human and murine MAPK pathway constituents. cDNA sequences and/or homologue(s) were identified using the BLAST (Basic Local Alignment Search Tool) computer program (National Center for Biotechnology Information, Bethesda, MD, USA). Primers were designed using the Primer3 computer program (Whitehead Institute, Cambridge, MA, USA) and the corresponding oligonucleotides (Table 1) were synthesized (Invitrogen).

\section{RNA extraction, reverse transcription and PCR}

Total RNA was extracted from bovine embryos (pools of 20 embryos/stage at the one-, two-, four-, and eight-cell, morula and blastocyst stages) using the phenol/chloroform method of Chomczynski \& Sacchi (1987). The total RNA extracts were digested with DNase 1 to eliminate possible contamination from genomic DNA. The reverse transcriptase $(\mathrm{RT})$ reactions were conducted using oligo-dT primers (Gibco BRL) as described previously (Barcroft et al. 1998, Offenberg et al. 2000, Natale et al. 2004). Briefly, samples were incubated for $90 \mathrm{~min}$ at $42^{\circ} \mathrm{C}$ in a total volume of $20 \mu$ consisting of $50 \mathrm{mM}$ Tris/ $\mathrm{HCl}(\mathrm{pH} \mathrm{8.3),} 75 \mathrm{mM} \mathrm{KCl}$, $3 \mathrm{mM} \mathrm{MgCl}_{2}, 10 \mathrm{mM}$ dithiothreitol, $0.5 \mathrm{mM}$ dNTPs, and 200 units of Superscript II (Gibco BRL) followed by heating the samples to $95^{\circ} \mathrm{C}$ for $5 \mathrm{~min}$ to terminate the reaction.

PCR was conducted using a protocol described previously (Barcroft et al. 1998, Offenberg et al. 2000, Natale et al. 2004). Briefly, two embryo equivalents for each stage of development under investigation were used per PCR reaction, which was repeated a minimum of three times from pools of three different developmental series of embryos. The primer sequences and the expected amplication sizes are given in Table 1. PCR products were resolved on $2.0 \%$ agarose gels containing $0.5 \mu \mathrm{g} / \mathrm{ml}$ ethidium bromide (Invitrogen). To confirm the specificity of each PCR product, representative amplicons were extracted from the gels and purified using a QIAquick Gel Extraction Kit (Qiagen, Mississauga, ON, Canada) and submitted for nucleotide sequencing (DNA Sequencing Facility, Robarts Research Institute, London, ON, Canada). The nucleotide sequence was subsequently compared with sequences available from the GenBank Nucleotide Sequence Database to confirm the specificity of each PCR product. Sequence homology ranged from 76 to $92 \%$ for bovine amplicons compared with known human sequences.

\section{Whole-mount indirect immunofluorescence}

To analyze the distribution of proteins encoding MAPK signaling pathway constituents during bovine preimplantation development, a whole-mount immunofluorescence technique described previously by Natale et al. (2004) for immunolocalization of p38 MAPK signaling molecules in mouse preimplantation embryos was used. Subsequently the immunofluorescence was detected using laser-scanning confocal microscopy as described previously (Barcroft et al. 1998).

Briefly, embryos at timed stages of development (oocytes, two-, four-, and eight-cell, morula and blastocyst stages) were washed in $1 \times \mathrm{PBS}$ and then fixed in $2 \%$ paraformaldehyde in PBS for 20 min at room temperature. These fixed embryos were washed in $1 \times$ PBS and either processed immediately for immuno-staining or stored at $4{ }^{\circ} \mathrm{C}$ in PBS $+0.09 \%$ sodium azide for a maximum of 3 weeks.

For immuno-staining, fixed embryos were permeabilized and blocked in $1 \times \mathrm{PBS}+5 \%$ donkey serum $+0.01 \%$ Triton $\mathrm{X}-100$ for $1 \mathrm{~h}$ at room temperature. Embryos were washed in $1 \times$ PBS and incubated with primary antibody diluted $1: 100$ in $1 \times$ PBS $+1 \%$ donkey serum $+0.005 \%$ Triton $\mathrm{X}-100$ for $1 \mathrm{~h}$ at room temperature followed by additional washes totaling $1 \mathrm{~h}$ at $37^{\circ} \mathrm{C}$. Primary antibodies were detected by exposure for $1 \mathrm{~h}$ to FITC-conjugated secondary antibodies (Jackson Immunoresearch Laboratories, Bar Harbour, ME, USA) diluted 1:200. Embryos were then treated with rhodamine-conjugated phalloidin $(5 \mu \mathrm{g} / \mathrm{ml} ; 1: 20)$ and DAPI $(1 \mathrm{mg} / \mathrm{ml}$; $1: 2000$ ) for $30 \mathrm{~min}$ at $37^{\circ} \mathrm{C}$ followed by two washes for $2 \mathrm{~h}$ each at $37^{\circ} \mathrm{C}$. Embryos were mounted in FluoroGuard antifade mounting reagent (BioRad, Mississauga,

Table 1 Nucleotide sequences for PCR amplification of MAPK-pathway constituents; namely p38 $\alpha, \beta, \gamma$ and $\delta$, MK2, and Hsp25/27.

\begin{tabular}{|c|c|c|c|}
\hline Gene product & Primer orientation & Primer sequence & Size $(b p)$ \\
\hline \multirow[t]{2}{*}{ p38 MAPK $\alpha$} & $5^{\prime}$ & GCCCCAGTAGTCAGAAGCAG & \multirow[t]{2}{*}{241} \\
\hline & $3^{\prime}$ & TAGGGGCTGAAGAGAGGTGA & \\
\hline \multirow[t]{2}{*}{ p38 MAPK $\beta$} & $5^{\prime}$ & GCTGTGAACGAGGACTGTGA & \multirow[t]{2}{*}{233} \\
\hline & $3^{\prime}$ & CGCTTCAGCTGGTCAATGTA & \\
\hline \multirow[t]{2}{*}{ p38 MAPK $\gamma$} & $5^{\prime}$ & GCTAAGGTGGCCATCAAGAA & \multirow[t]{2}{*}{181} \\
\hline & $3^{\prime}$ & ACGGCATCACCAGGTAAAAG & \\
\hline \multirow[t]{2}{*}{ p38 MAPK $\delta$} & $5^{\prime}$ & СТСАСССАТСССТTСТTTGA & \multirow[t]{2}{*}{243} \\
\hline & $3^{\prime}$ & ATACTGGTCCTTGGGCAGTG & \\
\hline \multirow[t]{2}{*}{ MK2 } & $5^{\prime}$ & AACGCCATCACCGACGACTAC & \multirow[t]{2}{*}{537} \\
\hline & $3^{\prime}$ & CAGGACTTCCGGAGCCACATA & \\
\hline \multirow[t]{2}{*}{ Hsp25/27 } & $5^{\prime}$ & СTCTTCGATCAAGCTTTCGG & \multirow[t]{2}{*}{393} \\
\hline & $3^{\prime}$ & CTCAGGGGATAGGGAAGAGG & \\
\hline
\end{tabular}


ON, Canada). Fluorescence patterns were examined using a Zeiss LSM 410 laser-scanning microscope with an inverted Axiovert 100 microscope under 20-40 $\times$ magnification. The images were then captured and stored as TIFF files by the Zeiss LSM software package.

All primary antibodies (p38, phospho-p38, MK2, phospho-MK2, Hsp25/27, phospho-Hsp25/27, ERK1/2 and phospho-ERK1/2) were obtained from Cell Signaling Technology (Beverly, MA, USA). The efficacy of phospho-p38 and phospho-ERK1/2 in detecting proteins extracted from granulosa cells of the bovine ovary was evaluated using Western blotting (data not shown).

\section{Pharmacological inhibition of the p38 and ERK MAPK pathways}

In vitro-produced and cultured eight-cell bovine embryos were treated with CSAID SB220025, an inactive analogue SB202474 or with vehicle alone (0.2\% DMSO in SOF). These pharmacological inhibitors specifically inhibit p38 MAPK $\alpha$ and $\beta$ isoforms at the concentrations used in this study (Jackson et al. 1998, Davidson \& Morange 2000, Cirillo et al. 2002, English \& Cobb 2002). Specifically, eight-cell bovine preimplantation embryos were divided into three treatment groups: (a) control (SOF + 0.2\% DMSO), (b) SOF + $20 \mu \mathrm{M}$ SB202474 (inactive analogue), and (c) SOF $+20 \mu \mathrm{M} \mathrm{SB220025.} \mathrm{A} \mathrm{similar}$ protocol was repeated using $10 \mu \mathrm{M}$ UO126, an inactive analogue, $10 \mu \mathrm{M} \cup 0124$, or vehicle alone (DMSO in SOF). These inhibitors are specific for the ERK1/2 MAPK pathway (Favata et al. 1998, Satoh et al. 2000)

In a final experimental series we conducted trials where eight-cell embryos were treated with a combination of both p38 MAPK- and ERK-pathway inhibitors. Eight-cell embryos were incubated in one of the following treatment groups: (a) control (SOF $+0.2 \%$ DMSO), (b) $\mathrm{SOF}+20 \mu \mathrm{M} \mathrm{SB} 202474$ (c) SOF $+20 \mu \mathrm{M} \mathrm{SB} 220025$, (d) $\mathrm{SOF}+10 \mu \mathrm{M}$ UO124, (e) SOF $+10 \mu \mathrm{M}$ UO126, and (f) $\mathrm{SOF}+20 \mu \mathrm{M}$ SB220025 $+10 \mu \mathrm{M}$ UO126. Embryos were removed at specific treatment times, including embryos treated for 5 days (long culture or LC) and embryos treated for 2 days and then placed into drug-free medium for 3 days (short culture or SC), for assessment of their development prior to fixation in $2 \%$ paraformaldehyde. Embryos were either processed for whole mount immunofluorescence immediately or they were stored in embryo-staining buffer for no longer than 3 weeks before processing.

\section{Statistical analysis}

The results are presented as the means \pm S.E.M. from three independent experiments. Statistical differences between time points were assessed by analysis of variance (ANOVA). Differences were considered significant when $P<0.05$. Significant differences between the means were determined using the least-significant-difference test.

\section{Results}

mRNA transcripts for constituents of the p38 MAPK signaling pathway

Transcripts encoding three of the four p38 MAPK isoforms $(\alpha, \beta$, and $\gamma), M K 2$, and $H s p 25 / 27$ were detected during bovine preimplantation embryo development (Fig. 1). Whereas the mRNA transcripts encoding p38 MAPK $\alpha$ and $\beta, M K 2$, and Hsp25/27 were detected in all developmental stages from the one-cell to the blastocyst stage, transcripts for p38 MAPK $\gamma$ were detected only in the early stages of preimplantation embryogenesis, i.e. two-, four-, and eight-cell stages. In addition, mRNA transcripts encoding p38 MAPK $\delta$ could not be detected in any of the stages of bovine preimplantation embryo development.

\section{Localization and distribution of p38 MAPK and ERK1/2 MAPK signaling pathway proteins in the preimplantation bovine embryo}

Whole-mount immunofluorescence revealed immunoreactive proteins for p38 MAPK and ERK1/2 pathways at timed stages of bovine preimplantation development (Fig. 2). p38 MAPK protein maintained a predominantly cytoplasmic distribution in all blastomeres from the onecell to the blastocyst stage. The localization pattern for the phosphorylated form of p38 MAPK completely mirrored the pattern observed for p38 MAPK protein.

In contrast, the MK2 immunofluorescence was found primarily within the cytoplasm at the two- and eight-cell stages; however, at the blastocyst stage MK2 protein immunofluorescence was concentrated more in the nucleus of each blastomere (Fig. 2). MK2 immunofluorescence

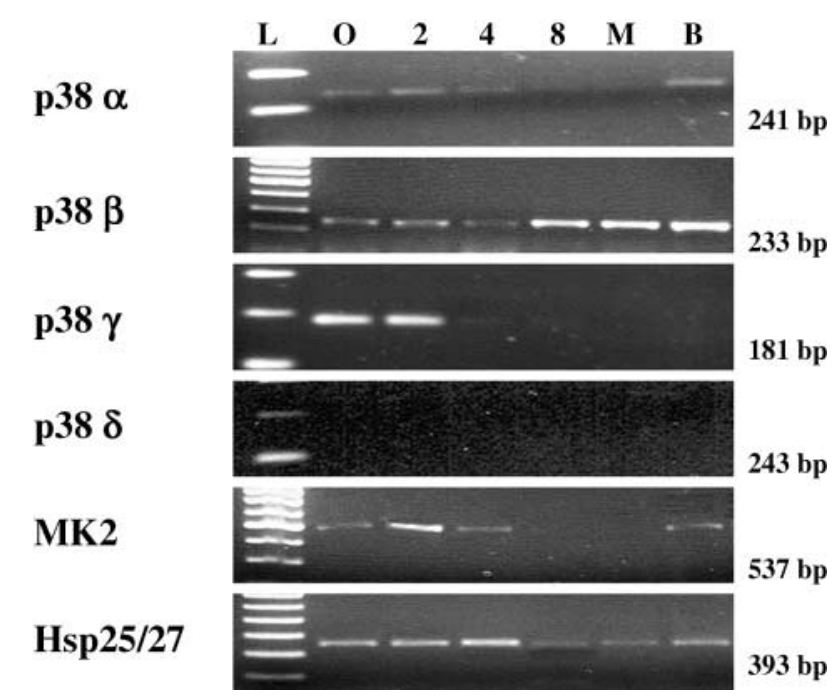

Figure 1 Detection of transcripts encoding p38 MAPK isoforms and ERK-pathway constituents during bovine preimplantation development. RT-PCR products encoding p38 MAPK $\alpha, \beta, \gamma$, and $\delta, M K 2$, and Hsp27 were investigated at timed stages of development $(\mathrm{O}$, matured oocytes; 2, two-cell; 4, four-cell; 8 , eight-cell; $M$, morula; B, blastocyst; L, ladder). 

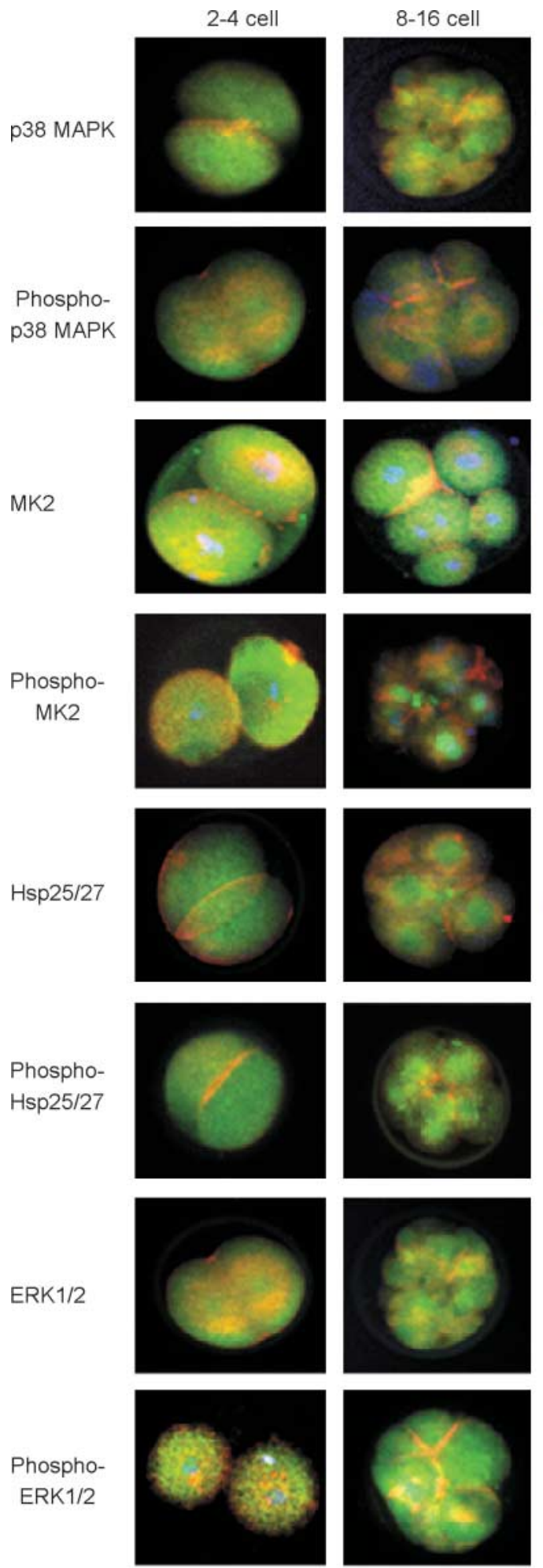
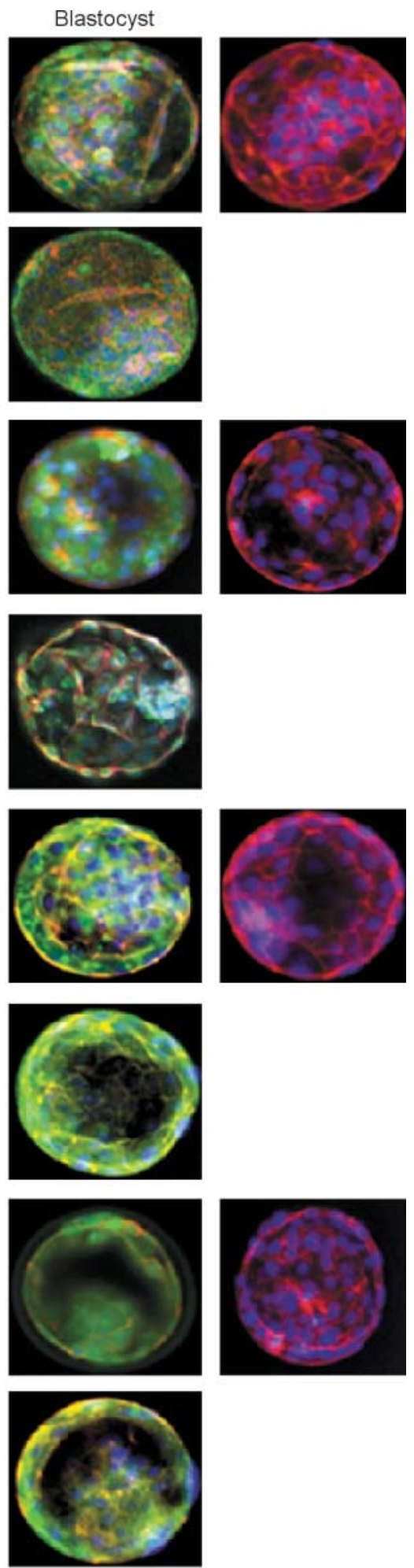

Figure 2 Distribution of p38 MAPK, phospho-p38 MAPK, MK2, phosphoMK2, Hsp25/27, phospho-Hsp25/27, ERK $1 / 2$, and phospho-ERK1/2 during bovine preimplantation embryo development at timed stages of development. Green, red, and blue colors in each representative photomicrograph indicate positive staining for the respective primary antibody, F-actin (rhodamine-phalloidin), and nuclei (DAPI) respectively. Control-panel photomicrographs are representative of embryos that were exposed to FITCconjugated secondary only (no primary antibody) in addition to rhodaminephalloidin and DAPI. was also detected throughout the trophectodermal cell cytoplasm (Fig. 2). The phospho-MK2 protein immunofluorescence mirrored that of the MK2 protein at the twocell stage (Fig. 2). However, from the eight-cell stage onward the phospho-MK2 protein expression differed from that of MK2 protein since it was observed predominantly in the nuclei of each blastomere (Fig. 2). This localization pattern for phospho-MK2 was maintained right up to the blastocyst stage. Hsp25/27 and phospho-Hsp25/27 were detected throughout all bovine preimplantation embryo 
stages (Fig. 2). At the two-cell stage, immunoreactive proteins for Hsp25/27 and phospho-Hsp25/27 were detected throughout the cytoplasm. Eight-cell-stage embryos, however, exhibited both nuclear as well as cytoplasmic localization. At the blastocyst stage, both Hsp25/27 and its phosphorylated form were co-localized with filamentous actin, as indicated by the yellow fluorescence that forms following merging of the green Hsp25/27 fluorescence with the red rhodamine-phallodin fluorescence. This colocalization of Hsp25/27 with the actin cytoskeleton was more prominent with the phosphorylated form of Hsp25/27. In addition to co-localization to actin, Hsp25/27 as well as phospho-Hsp25/27 could be detected in the cytoplasm.

During all the stages of preimplantation embryogenesis in the bovine embryo, ERK1/2 and phospho-ERK1/2 proteins displayed cytoplasmic and nuclear distribution at the two- and eight-cell stages (Fig. 2). However at the blastocyst stage, whereas ERK1/2 was detected both in the nucleus and cytoplasm of trophectodermal cells, its phosphorylated form was only detected in the cytoplasm associated with the actin cytoskeleton (Fig. 2).

\section{Inhibition of the p38 MAPK signaling pathway in the bovine embryo}

The treatment of eight-cell bovine embryos with $20 \mu \mathrm{M}$ SB220025, a specific inhibitor of p38 MAPK $\alpha / \beta$ isoforms, did not result in any significant differences in the proportion of embryos progressing to the blastocyst stage as compared with untreated controls. In addition, SB220025 treatment did not affect the timing of cavitation, as embryos in all three treatment groups progressed to the blastocyst stage at the same time (Fig. 3).
Having ascertained that p38 MAPK $\alpha / \beta$ isoform inhibition does not block bovine preimplantation embryogenesis, we focused our attention on blocking the ERK1/2 pathway. Treatment of eight-cell embryos with $10 \mu \mathrm{M}$ UO126, a specific inhibitor of ERK1/2, also did not result in any significant differences in the proportion of eightcell embryos that progressed to the blastocyst stage as compared with untreated controls and embryos treated with UO124 the inactive analogue. Those embryos treated with UO126 also underwent cavitation at the same times as observed in control groups (Fig. 3).

In our next experiment we investigated whether blockade of both p38 MAPK and ERK pathways affected bovine preimplantation development. Although the inactive inhibitors and control groups displayed a similar developmental frequency and were blastocysts by days 7-9, the group of embryos treated with the combination of SB220025 and UO126 (LC) failed to develop to the blastocyst stage. Most of the embryos in the LC group were halted at about the eight-to-16-cell stage (Fig. 3). Likewise, for eight-cell-stage embryos treated with both SB220025 and UO126 together for only $48 \mathrm{~h}$ (SC) prior to removal from these treatments and placement in fresh drug-free culture medium only a very small proportion of these treated embryos progressed to the blastocyst stage (Fig. 3). Thus we conclude that treatment of bovine zygotes with both inhibitors for $48 \mathrm{~h}$ or longer significantly reduces development to the blastocyst stage.

\section{Effect of p38 MAPK and ERK inhibitors on phosphorylation of downstream proteins}

In order to assess the ability of pharmacological inhibitors SB220025 and UO126 to inhibit p38 MAPK and ERK pathway constituents, either individually or in tandem,

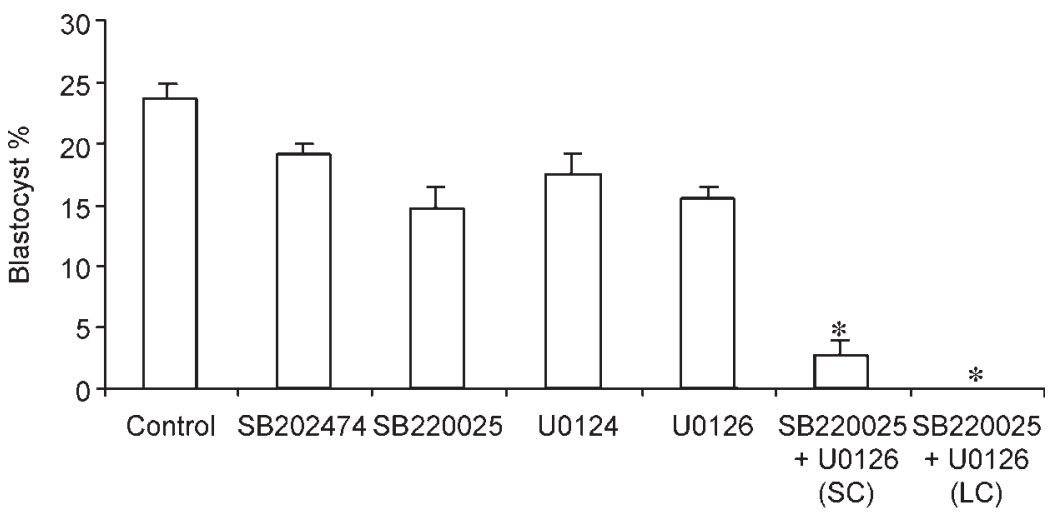

Treatment

Figure 3 The effect of treatment with pharmacological inhibitors of the p38 MAPK or ERK pathway on preimplantation bovine embryos. Eightcell embryos were treated in culture with $0 \mu \mathrm{M}$ (Control), p38 MAPK-inactive analogue SB202474 (20 $\mu \mathrm{M})$, p38 MAPK-active inhibitor SB220025 (20 $\mu \mathrm{M})$, ERK1/2-inactive analogue UO124 (10 $\mu \mathrm{M})$, ERK1/2-active inhibitor UO126 (10 $\mu \mathrm{M}), 20 \mu \mathrm{M} \mathrm{SB} 220025+10 \mu \mathrm{M}$ UO126 treated for 2 days (SC), and $20 \mu \mathrm{M} \mathrm{SB} 220025+10 \mu \mathrm{M}$ UO126 treated for 5 days (LC). Treatment with specific inhibitors alone or with their inactive analogues did not result in any significant differences $(P<0.05)$ in the proportion of eight-cell embryos that progressed to the blastocyst stage However, with both p38 MAPK and ERK1/2 inhibitors there was a significant reduction $(*)$ in the developmental competency of the eightcell embryos. Most of the embryos in the LC group were halted at about the eight-to-16-cell stage and none of them developed to the blastocyst stage. In the SC group, a very small proportion of treated embryos progressed to the blastocyst stage. 
we investigated the phosphorylation of the downstream substrates MK2 and Hsp25/27 after treatment with specific inhibitors. Whole-mount indirect immunofluorescence was used to evaluate the phosphorylation state of p38 MAPK, ERK1/2, MK2, and Hsp25/27. The control groups displayed fluorescence patterns consistent with those already described for phospho-p38 MAPK, phosphoERK1/2, phospho-MK2, and phospho-Hsp25/27 (Fig. 4). In embryos treated with either of the pharmacological inhibitors alone, there were no significant differences in the phospho-immunofluorescence patterns from that of controls. This result was unexpected and indicates that phosphorylation of these downstream kinases is not completely dependent upon maintaining activity of upstream p38 MAPK or MEK (MAPK/ERK kinase) kinases in this species. However, when the combination of p38 MAPK and ERK inhibitors were used, phosphofluorescence of phospho-p38 MAPK, phospho-MK2, phospho-Hsp25/27, and phospho-ERK1/2 (Fig. 4) were downregulated in the eight-to-16-cell-stage embryos.

\section{Effect of p38 MAPK and ERK inhibitors on embryonic actin}

Our previous studies have demonstrated that p38 MAPK is a potent regulator of filamentous actin in the mouse

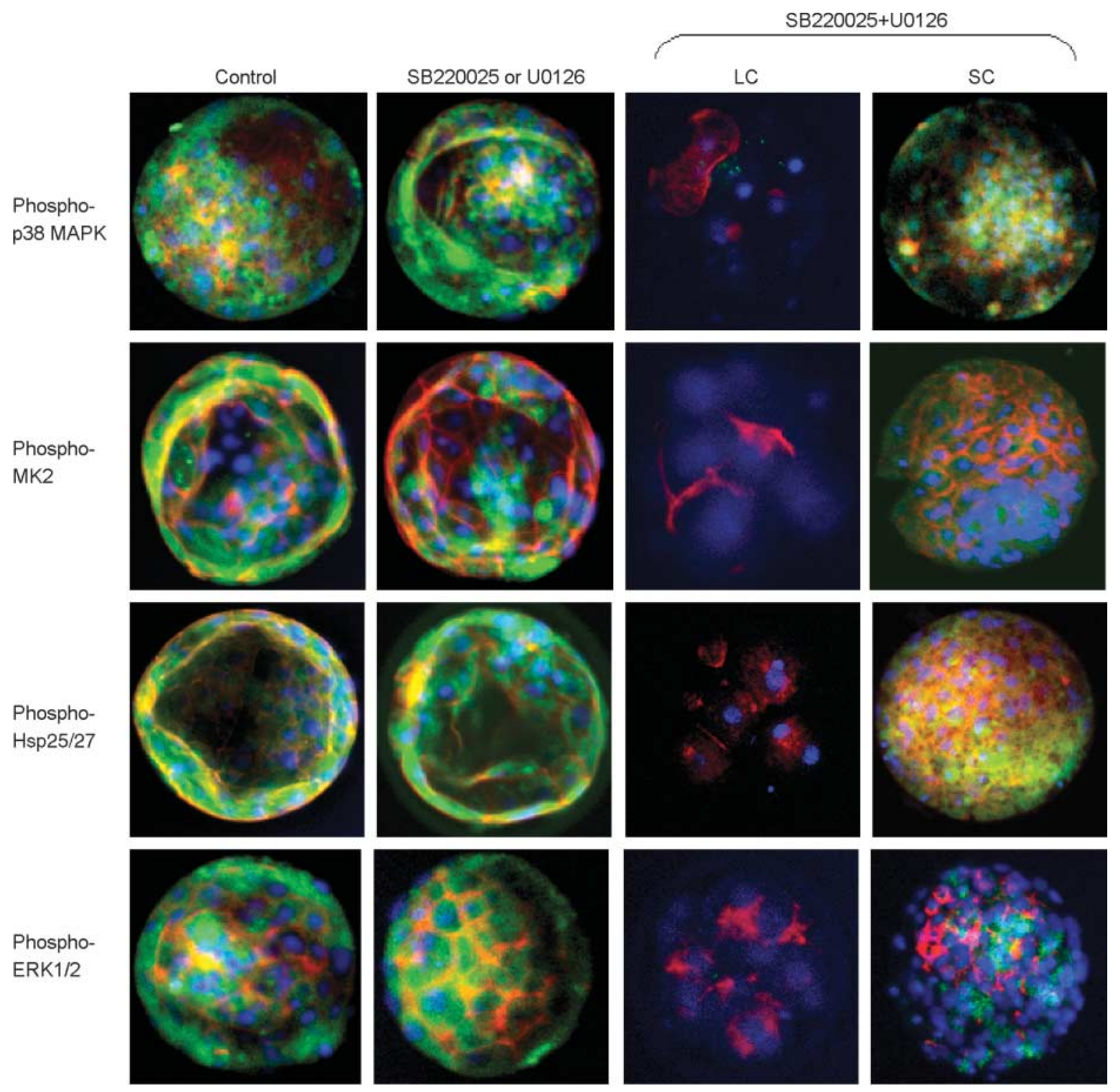

Figure 4 Distribution of phospho-p38 MAPK, phospho-MK2, phospho-Hsp25/27, and phospho-ERK1/2 during bovine preimplantation embryo development after exposure to either SB220025 or UO126, or both, at timed stages of development. Green, red, and blue colors in each representative photomicrograph indicate positive staining for respective primary antibody, F-actin (rhodamine-phalloidin), and nuclei (DAPI) respectively. SC represents embryos kept in specific inhibitors for $48 \mathrm{~h}$ and LC for $96 \mathrm{~h}$. 
embryo. Therefore, we also investigated the effect of specific MAPK inhibitors on actin cytoskeleton of the developing bovine preimplantation embryo. Filamentous actin was evaluated using rhodamine-phalloidin immunofluorescence as demonstrated previously using mouse embryos (Natale et al. 2004, Paliga et al. 2005). Whereas embryos treated with individual inhibitors showed identical filamentous actin patterns to that of controls, embryos treated with the combination of inhibitors displayed a marked reduction in rhodamine-phalloidin fluorescence by the eight-to-16-cell stage (Fig. 4). However, in a small number of SC embryos treated for only $48 \mathrm{~h}$ that developed to the blastocyst stage, there was not only a marked reduction in the rhodamine-phalloidin immunofluorescence but also distinct loss of pattern. The filamentous actin appeared indistinct as compared with the controls, where filamentous actin was localized at trophectodermal cell junctions.

\section{Discussion}

This study investigates, for the first time, the role of MAPK signaling during bovine preimplantation embryo development. We have determined that mRNAs and proteins encoding the principal constituents of the p38 MAPK pathway are present throughout the first 8 days of bovine preimplantation development, similar to what we have already reported for the mouse preimplantation embryo (Natale et al. 2004, Paliga et al. 2005),. However, our results demonstrate that bovine preimplantation development (unlike that observed for mouse preimplantation development) is not dependent upon p38 MAPK activity. Treatment of mouse embryos with SB220025 at either the two-, four-, or eight-cell stage of development results in a reversible developmental blockade at the eight-to-16-cell stage (Natale et al. 2004, Paliga et al. 2005). Our present study has demonstrated that treatment of eight-cell bovine preimplantation embryos with the same inhibitor does not affect development to the blastocyst. Furthermore, treatment with SB220025 does not result in a loss of downstream kinase (MK2 or Hsp25/27) phosphorylation in the bovine embryo as it does in the mouse early embryo (Natale et al. 2004, Paliga et al. 2005). This suggests that, in the bovine preimplantation embryo, alternative pathways also regulate the downstream targets of p38 MAPK activation. In the mouse early embryo it would appear that p38 MAPK is the primary if not sole activator of MK2 and thus Hsp25/27 at the eight-to-16-cell stage (Natale et al. 2004, Paliga et al. 2005). To investigate this further, we conducted experiments with an inhibitor of the ERK MAPK pathway, UO126. Bovine preimplantation embryos treated alone with UO126 did not display an impaired ability to develop to the blastocyst stage. This result is in accordance with outcomes from similar experiments applied to the mouse embryo, suggesting that the ERK pathway is not required to sustain development to the blastocyst stage (Haraguchi et al. 1998, Natale et al. 2004). When both inhibitors are combined, we observed an unexpected outcome. Bovine early embryos treated with both SB220025 and UO126 displayed a developmental blockade at the eight-to-16-cell stage and did not complete development to the blastocyst stage. The results suggest that there are important species differences in the activation and function of MAPK signaling. For the bovine species, it is likely that the ERK pathway is capable of activating p38 MAPK downstream kinases in the absence of p38 MAPK activity to maintain development to the blastocyst stage. Thus bovine embryos require both p38 MAPK and ERK signaling for their development to the blastocyst stage.

MAPK pathways regulate several cellular processes, including cell proliferation, growth, differentiation, and death (Kyriakis \& Avruch 2001, Ravingerova et al. 2003, Ji 2004). Generation of a p38 $\alpha$ MAPK-null mouse line demonstrated that $\mathrm{p} 38 \alpha$ MAPK is a key regulator of placental formation but not of preimplantation development, as the null mutants in this line display an embryonic lethality associated with placental defects (Adams et al. 2000, Allen et al. 2000, Mudgett et al. 2000). As several p38 MAPK isoforms have been identified in murine embryos (Natale et al. 2004), it is likely that other isoforms compensate for the loss of the $p 38 \alpha$ isoform in the null line. This was subsequently proven when simultaneous inhibition of $p 38 \alpha / \beta$ impeded the development of murine embryos to the blastocyst stage (Natale et al. 2004). However, no information has been available until now on the role of MAPK signaling in the bovine embryo and it is imperative that experiments contrast the expression and activation of MAPK pathways in species beyond the mouse. Using a gene-specific RT-PCR technique we have identified mRNA transcripts encoding p38 MAPK isoforms $(\alpha, \beta$, and $\gamma), M K 2$, and Hsp25/27 in the bovine embryo. That we could not detect p38 MAPK $\delta$ isoform in the bovine preimplantation embryo at any of the developmental stages under study could signify that $\mathrm{p} 38 \delta$ is not required by the bovine preimplantation embryo during these early stages of development. This result is in contrast to what was observed in the mouse preimplantation embryo as mRNAs encoding both the $\gamma$ and $\delta$ p38 MAPK isoforms were detected throughout preimplantation development in this species (Natale et al. 2004).

Although the expression of p38 MAPK $\alpha$ and $\beta$, MK2, and Hsp25/27 were observed throughout bovine preimplantation development, expression of p38 MAPK $\gamma$ could be detected only at the early stages of preimplantation embryo, i.e. from oocyte to eight-cell stages. This suggests that whereas the pattern of expression for p38 MAPK $\alpha$ and $\beta$, MK2, and Hsp27 is both maternal and embryonic, p38 MAPK $\gamma$ shows only a maternal pattern of expression. The maternal-to-embryonic transition is a crucial phase in early development that occurs at the eight-cell stage in bovine embryos and is characterized by onset of transcription and subsequent translation of mRNA transcripts 
(Telford et al. 1990, Memili et al. 1998, Natale et al. 2000, Schultz 2002).

Although the expression patterns of p38 MAPK isoform transcripts in the bovine embryo differ from those of murine embryos (Natale et al. 2004), the data still support the presence of an active p38 MAPK pathway in the bovine preimplantation embryo. Environmental/culture stresses, such as changes in osmolarity, temperature, oxygen tension, and oxygen radical metabolites, are activators of p38 MAPK (Ono \& Han 2000). Since, embryos are exposed to such conditions both in vitro and in vivo it is quite likely that p38 MAPK signaling could be playing an important role in mediating and transmitting signals from the environment and thereby play a role in coordinating bovine embryonic development.

Localization of specific proteins of the MAPK pathway indicates that p38 MAPK, MK2, Hsp27, and ERK proteins are present in the bovine preimplantation embryo from the two-cell to the blastocyst stage. Since all these proteins were also identified in their phosphorylated forms, this provides further evidence that these proteins are active and play a distinct role in these early stages of development. Whereas p38 MAPK and ERK1/2 proteins show a similar distribution, with the proteins being present both in the cytoplasm and the nucleus in the blastomeres of the cleavage stages and also in the trophectodermal cells of the blastocyst, MK2 showed a distinct shift in its localization pattern. Although MK2 protein could be detected in both the nuclei and cytoplasm, its phosphorylated form was present predominantly only in the nuclei, suggesting that once MK2 is phosphorylated it becomes associated with the nuclei. This is in accordance with other studies that have shown that MK2 phosphorylation is triggered in response to p38 activation, which in turns stimulates Hsp25/27 phosphorylation (Stokoe et al. 1992, New \& Han 1998). The localization pattern observed for Hsp25/27 during bovine early development suggests that once Hsp25/27 becomes phosphorylated, it associates with the actin cytoskeleton. This is in accordance with several other studies demonstrating that Hsp25/27 interacts with the actin cytoskeleton (Landry \& Huot 1995, Davidson \& Morange 2000, DalleDonne et al. 2001, Natale et al. 2004). It can be concluded that the p38 MAPK pathway is active in the bovine embryo.

Immunolocalization of ERK proteins was predominantly cytoplasmic in the early cleavage stages; however, at the blastocyst stage some of the trophectodermal cells also showed a nuclear presence of this protein. It can be concluded that ERK protein was localized in the cytoplasm and the nucleus, suggesting that the ERK pathway is also active in bovine embryos. This finding is different from that in mouse where there are conflicting reports about the role of ERK in preimplantation embryogenesis (Haraguchi et al. 1998, Iwamori et al. 2000, Wang et al. 2004). It has been suggested that ERK is not phosphorylated at any stage during the cell cycle of the mouse early embryos
(Iwamori et al. 2000); although ERK proteins are expressed, MAPKs other than ERKs are activated during the early cleavage divisions of mouse embryos (Haraguchi et al. 1998). However, recently it has been reported that ERK1/2 mRNA could be detected from the oocyte to the blastocyst stage in the mouse embryo and, in addition, ERK1/2 proteins are activated by phosphorylation (Wang et al. 2004).

The most important finding of our study is that pharmacological inhibition of p38 MAPK during bovine embryo development had a different outcome from that of our previous studies in mouse (Natale et al. 2004, Paliga et al. 2005). In mouse, a significant number of two-cell embryos incubated with either 2.0 or $20 \mu \mathrm{M}$ SB220025 failed to progress to the blastocyst stage and halted their development at the eight-to16-cell stage (Natale et al. 2004). Similar results were achieved when eight-cell mouse embryos were treated with SB220025 (Paliga et al. 2005). However, treatment of bovine embryos with $20 \mu \mathrm{M}$ SB220025 at the eight-cell stage failed to induce any developmental blockade and a normal rate of development to the blastocyst stage was observed. Treatment of eight-cell bovine embryos with $10 \mu \mathrm{M}$ UO126 also did not affect embryo development negatively. This is consistent with findings that the ERK-null murine line progresses through preimplantation development without problem (Saba-El-Leil et al. 2003). The results of our present study certainly suggest that in the bovine embryo the ERK pathway is able to compensate when p38 MAPK is blocked and that when this compensatory pathway is also blocked, p38 MAPK-blocked embryos fail to progress to the blastocyst stage.

In support of this view, when embryos were treated with SB220025 alone the levels and patterns of phosphoMK2 and phospho-Hsp27 localization were maintained, suggesting that an alternative mechanism might be activating these kinases in the absence of p38 MAPK activity. Similar results were seen when embryos were cultured in the presence of the ERK inhibitor UO126 alone. A number of studies have demonstrated that several signaling-pathway constituents are held in common between parallel MAPK pathways (Kyriakis \& Avruch 2001, Zhang \& Liu 2002, Cowan \& Storey 2003, Ravingerova et al. 2003). We would propose that when the p38 MAPK pathway is inhibited, the ERK pathway might be compensating for the loss of p38 MAPK. An alternative possibility is that an additional MAPK pathway such as the JNK/SAPK or big MAPK pathway might be active in the preimplantation embryo. Our results would suggest, however, that neither of these pathways is capable of compensating for the loss of both the ERK and p38 MAPK pathways as blastocyst formation was blocked in the presence of both p38 MAPK and ERK inhibitors. Further studies are required to ascertain the reason for this.

An additional difference observed in this study as compared with that from studies applied to the mouse embryo was that whereas treatment with p38 MAPK inhibitors 
lead to a complete loss of filamentous actin in eight-to16-cell murine embryos, there was a marked down-regulation of filamentous actin in bovine embryos cultured in the presence of both p38 MAPK and ERK-pathway inhibitors but the rhodamine-phalloidin fluorescence never completely disappeared. This result also suggests that the regulation of filamentous actin is more complex in the bovine embryo and may be subject to multiple pathways, whereas in the eight-to-16-cell mouse embryo p38 MAPK is the dominant if not exclusive pathway that regulates actin (Natale et al. 2004, Paliga et al. 2005). In conclusion, this is the first study to investigate the role of p38 MAPK signaling in bovine preimplantation embryos. We report that the mechanism of MAPK signaling in the bovine embryo differs from that of the murine embryo. Unlike mouse embryos, inhibition of p38 MAPK individually did not significantly disrupt development to the blastocyst stage. However, when both inhibitors were combined, there was a significant reduction in the immunofluorescence of phosphorylated downstream mediators of MAPK signaling and a blockade of development to the blastocyst stage. In view of these observations, it can be concluded that in variance to what was observed during murine preimplantation development, bovine early embryos do not rely exclusively on p38 MAPK activity to complete development to the blastocyst stage.

\section{Acknowledgements}

Work was supported by funds from the Canadian Institute for Health Research (CIHR), Canada. We thank Julie Andrassy, Barry Fong, and Michelle Violette for assistance with ovary and embryo collections. A J W is a recipient of a Premier's Research Excellence Award by the Ontario Provincial Government. The authors declare that there is no conflict of interest that would prejudice the impartiality of this scientific work.

\section{References}

Adams RH, Porras A, Alonso G, Jones M, Vintersten K, Panelli S, Valladares A, Perez L, Klein R \& Nebreda AR 2000 Essential role of p38alpha MAP kinase in placental but not embryonic cardiovascular development. Molecular Cell 6 109-116.

Ali A \& Sirard MA 2002 Effect of the absence or presence of various protein supplements on further development of bovine oocytes during in vitro maturation. Biology of Reproduction 66 901-905.

Allen M, Svensson L, Roach M, Hambor J, McNeish J \& Gabel CA 2000 Deficiency of the stress kinase p38alpha results in embryonic lethality: characterization of the kinase dependence of stress responses of enzyme-deficient embryonic stem cells. Journal of Experimental Medicine 191 859-870.

Barcroft LC, Hay-Schmidt A, Caveney A, Gilfoyle E, Overstrom EW, Hyttel P \& Watson AJ 1998 Trophectoderm differentiation in the bovine embryo: characterization of a polarized epithelium. Journal of Reproduction and Fertility 114 327-339.

Boulton TG \& Cobb MH 1991 Identification of multiple extracellular signal-regulated kinases (ERKs) with antipeptide antibodies. Cell Regulation 2 357-371.

Chomczynski P \& Sacchi N 1987 Single-step method of RNA isolation by acid guanidinium thiocyanate-phenol-chloroform extraction. Analytical Biochemistry 162 156-159.
Cirillo PF, Pargellis C \& Regan J 2002 The non-diaryl heterocycle classes of p38 MAP kinase inhibitors. Current Topics in Medicinal Chemistry 2 1021-1035.

Cowan KJ \& Storey KB 2003 Mitogen-activated protein kinases: new signaling pathways functioning in cellular responses to environmental stress. Journal of Experimental Biology 206 1107-1115.

Dalle-Donne I, Rossi R, Milzani A, Di Simplicio P \& Colombo R 2001 The actin cytoskeleton response to oxidants: from small heat shock protein phosphorylation to changes in the redox state of actin itself. Free Radical Biology Medicine 31 1624-1632.

Davidson SM \& Morange M 2000 Hsp25 and the p38 MAPK pathway are involved in differentiation of cardiomyocytes. Developmental Biology 218 146-160.

English JM \& Cobb MH 2002 Pharmacological inhibitors of MAPK pathways. Trends in Pharmacological Sciences 23 40-45.

Enslen H, Brancho DM \& Davis RJ 2000 Molecular determinants that mediate selective activation of p38 MAP kinase isoforms. EMBO J $191301-1311$.

Favata MF, Horiuchi KY, Manos EJ, Daulerio AJ, Stradley DA, Feeser WS, Van Dyk DE, Pitts WJ, Earl RA \& Hobbs F et al. 1998 Identification of a novel inhibitor of mitogen-activated protein kinase kinase. Journal of Biological Chemistry 273 18623-18632.

Giritharan G \& Rajamahendran R 2001 In vitro embryo production using ovaries removed from culled cows. Canadian Journal of Animal Science $\mathbf{8 1}$.

Guay J, Lambert H, Gingras-Breton G, Lavoie JN, Huot J \& Landry J 1997 Regulation of actin filament dynamics by p38 map kinasemediated phosphorylation of heat shock protein 27. Journal of Cell Science 110 (Pt 3) 357-368.

Han J, Lee JD, Bibbs L \& Ulevitch RJ 1994 A MAP kinase targeted by endotoxin and hyperosmolarity in mammalian cells. Science $\mathbf{2 6 5}$ $808-811$.

Haraguchi S, Naito K \& Sato E 1998 MAP kinase cascade, but not ERKs, activated during early cleavage of mouse embryos. Molecular Reproducation and Development 51 148-155.

Holm P, Booth PJ, Schmidt MH, Greve T \& Callesen H 1999 High bovine blastocyst development in a static in vitro production system using SOFaa medium supplemented with sodium citrate and myo-inositol with or without serum-proteins. Theriogenology $\mathbf{5 2}$ $683-700$

Huot J, Houle F, Rousseau S, Deschesnes RG, Shah GM \& Landry J 1998 SAPK2/p38-dependent F-actin reorganization regulates early membrane blebbing during stress-induced apoptosis. Journal Cell Biology 143 1361-1373.

Iwamori N, Naito K, Sugiura K, Kagii H, Yamashita M, Ohashi S, Goto S, Yamanouch K \& Tojo H 2000 Phosphorylation of mitogenactivated protein kinase cascade during early embryo development in the mouse. Reproduction, Fertility and Development 12 209-214.

Jackson JR, Bolognese B, Hillegass L, Kassis S, Adams J, Griswold DE \& Winkler JD 1998 Pharmacological effects of SB 220025, a selective inhibitor of P38 mitogen-activated protein kinase, in angiogenesis and chronic inflammatory disease models. Journal of Pharmacology and Experimental Therapeutics 284 687-692.

Ji RR 2004 Mitogen-activated protein kinases as potential targets for pain killers. Current Opinion in Investigational Drugs 5 71-75.

Khurana A \& Dey CS 2003 p38 MAPK interacts with actin and modulates filament assembly during skeletal muscle differentiation. Differentiation 71 42-50.

Kyriakis JM \& Avruch J 2001 Mammalian mitogen-activated protein kinase signal transduction pathways activated by stress and inflammation. Physiology Reviews 81 807-869.

Landry J \& Huot J 1995 Modulation of actin dynamics during stress and physiological stimulation by a signaling pathway involving p38 MAP kinase and heat-shock protein 27. Biochemistry and Cell Biology 73 703-707.

Lavoie JN, Lambert H, Hickey E, Weber LA \& Landry J 1995 Modulation of cellular thermoresistance and actin filament stability accompanies phosphorylation-induced changes in the oligomeric 
structure of heat shock protein 27. Molecular Cell Biology 15 505-516.

Lee JD, Ulevitch RJ \& Han J 1995 Primary structure of BMK1: a new mammalian map kinase. Biochemical and Biophysical Research Communications 213 715-724.

Memili E, Dominko T \& First NL 1998 Onset of transcription in bovine oocytes and preimplantation embryos. Molecular Reproduction and Development 51 36-41.

Mudgett JS, Ding J, Guh-Siesel L, Chartrain NA, Yang L, Gopal S \& Shen MM 2000 Essential role for p38alpha mitogen-activated protein kinase in placental angiogenesis. PNAS 97 10454-10459.

Natale DR, Kidder GM, Westhusin ME \& Watson AJ 2000 Assessment by differential display-RT-PCR of mRNA transcript transitions and alpha-amanitin sensitivity during bovine preattachment development. Molecular Reproduction and Development 55 152-163.

Natale DR, Paliga AJ, Beier F, D'Souza SJ \& Watson AJ 2004 p38 MAPK signaling during murine preimplantation development. Developmental Biology 268 76-88.

New L \& Han J 1998 The p38 MAP kinase pathway and its biological function. Trends in Cardiovascular Medicine 8 220-228.

Niemann H \& Wrenzycki C 2000 Alterations of expression of developmentally important genes in preimplantation bovine embryos by in vitro culture conditions: implications for subsequent development. Theriogenology 53 21-34.

Niemann H, Wrenzycki C, Lucas-Hahn A, Brambrink T, Kues WA \& Carnwath JW 2002 Gene expression patterns in bovine in vitroproduced and nuclear transfer-derived embryos and their implications for early development. Cloning Stem Cells 4 29-38.

Offenberg H, Barcroft LC, Caveney A, Viuff D, Thomsen PD \& Watson AJ 2000 mRNAs encoding aquaporins are present during murine preimplantation development. Molecular Reproduction and Development 57 323-330.

Ono K \& Han J 2000 The p38 signal transduction pathway: activation and function. Cell Signal 12 1-13.

Paliga AJ, Natale DR \& Watson AJ 2005 p38 mitogen activated protein kinase (MAPK) regulates actin and compaction during murine pre-implantation development. Biologie Cellulaire (submitted).

Pouyssegur J, Volmat V \& Lenormand P 2002 Fidelity and spatiotemporal control in MAP kinase (ERKs) signalling. Biochemical Pharmacology 64 755-763.

Ravingerova T, Barancik M \& Strniskova M 2003 Mitogen-activated protein kinases: a new therapeutic target in cardiac pathology. Molecular and Cellular Biochemistry 247 127-138.

Saba-El-Leil MK, Vella FD, Vernay B, Voisin L, Chen L, Labrecque N, Ang SL \& Meloche S 2003 An essential function of the mitogen-activated protein kinase Erk2 in mouse trophoblast development. EMBO Reports 4 964-968.

Satoh T, Nakatsuka D, Watanabe Y, Nagata I, Kikuchi H \& Namura S 2000 Neuroprotection by MAPK/ERK kinase inhibition with U0126 against oxidative stress in a mouse neuronal cell line and rat primary cultured cortical neurons. Neuroscience Letters 288 $163-166$.

Schultz RM 2002 The molecular foundations of the maternal to zygotic transition in the preimplantation embryo. Human Reproduction Update 8 323-331.

Stokoe D, Engel K, Campbell DG, Cohen P \& Gaestel M 1992 Identification of MAPKAP kinase 2 as a major enzyme responsible for the phosphorylation of the small mammalian heat shock proteins. FEBS Letters 313 307-313.

Telford NA, Watson AJ \& Schultz GA 1990 Transition from maternal to embryonic control in early mammalian development: a comparison of several species. Molecular Reproduction and Development 26 90-100.

Vigneault C, McGraw S, Massicotte L \& Sirard MA 2004 Transcription factor expression patterns in bovine in vitro-derived embryos prior to maternal-zygotic transition. Biology of Reproduction $\mathbf{7 0}$ $1701-1709$.

Wang Y, Wang F, Sun T, Trostinskaia A, Wygle D, Puscheck E \& Rappolee DA 2004 Entire mitogen activated protein kinase (MAPK) pathway is present in preimplantation mouse embryos. Developmental Dynamics 231 72-87.

Watson AJ \& Barcroft LC 2001 Regulation of blastocyst formation. Frontiers in Bioscience 6 D708-D730.

Whitmarsh AJ \& Davis RJ 2001 Analyzing JNK and p38 mitogenactivated protein kinase activity. Methods in Enzymology 332 319-336.

Woodgett JR, Avruch J \& Kyriakis J 1996 The stress activated protein kinase pathway. Cancer Surveys 27 127-138.

Zhang W \& Liu HT 2002 MAPK signal pathways in the regulation of cell proliferation in mammalian cells. Cell Research 12 9-18.

Zhou G, Bao ZQ \& Dixon JE 1995 Components of a new human protein kinase signal transduction pathway. Journal of Biological Chemistry $27012665-12669$.

Received 2 November 2004

First decision 26 November 2004

Revised manuscript received 11 February 2005

Accepted 21 February 2005 